\title{
Espaços verdes medicinais em escolas públicas do município de Palmeira das Missões, RS
}

\author{
Green spaces medicinal in public schools of Palmeira das Missões, RS \\ Caroline Battisti', Roberta Klein Horbach', Tânea Maria Bisognin Garlet ${ }^{2}$ \\ 'Acadêmica do curso de Ciências Biológicas UFSM - Palmeira das Missões. \\ 'Acadêmica do curso de Ciências Biológicas UFSM - Palmeira das Missões. \\ 2Docente do Departamento Zootecnia e Ciências Biológicas UFSM - Palmeira das Missões.
}

\section{Resumo}

A utilização de plantas pelas civilizações faz parte da cultura, como resultado das experiências de gerações passadas, que foram transmitidas por meio de aprendizagem consciente e inconsciente. Este trabalho teve por objetivo a implantação de espaços verdes medicinais em três escolas públicas do município de Palmeira das Missões, Rio Grande do Sul. As atividades foram desenvolvidas no período de abril a dezembro de 2012 e envolveram toda a comunidade escolar. O levantamento dos dados foi feito com a aplicação de questionários e a partir desse foram desenvolvidas palestras, oficinas e o cultivo de espécies medicinais, condimentares e aromáticas. O trabalho permitiu a integração entre a universidade e as escolas e tornou possível associar o conhecimento empírico ao científico, e, assim, não só despertar cuidados com a saúde, mas também o interesse em usar e preservar a flora medicinal.

Palavras Chave: Cultivo; Plantas medicinais; Etnobotânica.

\begin{abstract}
The use of plants for civilizations is part of the culture as a result of the experiences of past generations, which were passed through conscious and unconscious learning. This study aimed to the implementation of green spaces medicinal in three public schools in Palmeira das Missões, Rio Grande do Sul. The activities were carried out from April to December 2012 and involved the whole school community. The survey was done with the use of questionnaires and from that were developed lectures, workshops and cultivation of plants medicinal, condiments and aromatic. The work allowed the integration between the university and schools making it possible to associate the empirical scientific knowledge, and thus not only awaken healthcare, but also interest in using and preserving the flora.
\end{abstract}

Keywords: Cultivation; Medicinal plants; Ethnobotany. 


\section{INTRODUÇÃO}

A utilização de plantas para o tratamento da saúde teve seu registro em diferentes épocas na história da humanidade e permanece até os dias de hoje fazendo parte da cultura de diferentes comunidades populacionais. Embora a medicina moderna esteja bem desenvolvida na maior parte do mundo, a Organização Mundial da Saúde (OMS) reconhece que grande parte da população dos países em desenvolvimento depende da medicina tradicional para sua atenção primária, tendo em vista que $80 \%$ desta população utilizam práticas tradicionais nos seus cuidados básicos de saúde e $85 \%$ destes utilizam plantas ou suas preparações (BRASIL, 2006).

O conhecimento popular sobre as plantas ultrapassou todas as barreiras durante o processo de desenvolvimento da civilização chegando até os dias atuais, sendo amplamente utilizado pela população como fonte de recurso terapêutico eficaz. O principal meio de perpetuação dos saberes se dá de forma oral. Em relação ao conhecimento popular, é importante saber de onde ele é originário, se é um conhecimento tradicional com base na experiência direta dos membros da comunidade ou se surgiu de contos de fontes externas à cultura local (DI STASI, 1996). A recuperação dessas informações é altamente necessária, tendo em vista que elas servem de subsídio para o conhecimento do potencial medicinal da flora, auxiliando substancialmente na discussão da questão do uso e manutenção da biodiversidade, além de vir a ser um instrumento de inserção das práticas acadêmicas na comunidade.

As atividades de extensão são desenvolvidas diretamente com a comunidade, sendo essa uma forma da universidade produzir conhecimento e socializá-lo com a população. Leita e Nunes (2009) destacam que as pessoas comuns financiam a universidade, em especial as universidades públicas, com isso, ressaltam que as ações de extensão devem ser desenvolvidas para gerar um retorno social. Segundo Silva (2011), as atividades de extensão universitária possibilitam então uma via de mão-dupla, cujo tráfego estabelece a troca de saberes acadêmicos e populares, tendo como consequência a democratização do conhecimento acadêmico e a participação efetiva da comunidade nas ações desenvolvidas pela universidade. A extensão é um trabalho interdisciplinar que favorece a visão integrada do social (ROCHA, 2001).

Portanto, sabendo da importância que a extensão tem na comunidade e observando os relatos destacados por Matos e Queiroz (2009) que crianças em contato com o verde demonstram um comportamento mais harmonioso e maior consciência em preservar o ambiente onde vivem, sugere-se a implantação de espaços verdes medicinais nas escolas públicas, visando à orientação da qualidade de vida dos envolvidos e a transformação individual e coletiva da comunidade. Pois um espaço verde medicinal dentro da escola se torna um ambiente público e de uso coletivo, que permite que as espécies ali cultivadas sejam utilizadas para tratar doenças simples, mas, além disso, desenvolve nos indivíduos que delas dela usufruem a responsabilidade mantê-las e preservá-las.

Os espaços verdes medicinais implantados nas escolas podem se transformar num laboratório vivo e se tornar uma estratégia para promover estudos, pesquisas, debates e atividades sobre a questão ambiental, além de estimular o trabalho pedagógico dinâmico, participativo, prazeroso, interdisciplinar (NEVES et al., 2010). Assim, nota-se a importância de ações efetivas por parte da comunidade universitária e que pode proporcionar a incorporação de saberes populares, enfatizando desta forma, a etnobotânica (BRASIL, 2007). O estudo das plantas que irão compor um espaço ou uma horta medicinal possibilita o resgate da cultura e história de cada região. Morgado e Santos (2009) dizem que a recuperação, reconhecimento e respeito da diversidade cultural, linguística e ecológica são possíveis a partir do estudo e conhecimento das plantas.

Com isso, o presente trabalho teve por objetivo a implantação de espaços verdes com plantas medicinais, condimentares e aromáticas em escolas da rede pública de Palmeira das Missões, RS, através de levantamento e seleção das plantas mais utilizadas pelas comunidades a fim de orientar sobre os cuidados básicos com a saúde e promover o conhecimento e a conservação da biodiversidade vegetal.

\section{MATERIAL E MÉTODOS}

O estudo foi desenvolvido em escolas públicas do município de Palmeira das Missões, localizado a $368 \mathrm{~km}$ de Porto Alegre, capital do Estado do Rio Grande do Sul, no período de abril a dezembro de 2012. Foram realizadas atividades que constaram da aplicação de questionários semiestruturados, apresentações, oficinas e práticas de cultivo das plantas medicinais, conforme a realidade de cada escola. 
As escolas da rede pública estadual foram contatadas por meio da $20^{\mathrm{a}}$ Coordenadoria Regional da Educação e selecionadas a partir da manifestação de interesse. Três escolas foram visitadas para diagnóstico do espaço físico disponível: uma localizada no interior do município e as outras duas na periferia da área urbana. Por questões éticas, estas serão tratadas como escolas A, B e C.

Primeiramente, foi aplicado um questionário, composto por perguntas referentes ao uso de plantas medicinais no ambiente familiar, além de dados socioculturais, com a finalidade de identificar os conhecimentos prévios da comunidade escolar sobre o assunto, e também, com o intuito de discriminar as plantas a serem trabalhadas. Essa atividade foi padrão em todas as escolas.

$\mathrm{O}$ questionário abordou as questões que estão relacionadas na figura 1.

Trezentos questionários foram entregues nas três escolas e a partir dos dados obtidos foram selecionadas as plantas com maior número de citações e com viabilidade de cultivo para apresentação e inserção nos espaços verdes escolares. A identificação das espécies foi feita no local, com auxílio de especialista na área.

\section{Atividades na escola $\mathrm{A}$}

Os alunos levaram os questionários para serem respondidos em casa, junto com seus familiares, sobre as plantas medicinais utilizadas e conhecidas. Essa atividade foi repetida em todas as escolas. Junto com os questionários, foi solicitado que os alunos trouxessem mudas e/ou fragmentos para identificação das espécies. A partir da análise desses questionários, uma apresentação sobre as espécies citadas foi elaborada e apresentada aos alunos e professores. Posteriormente, iniciaram-se as atividades de cultivo com os alunos do $6^{\circ}$ ano e $8^{\mathrm{a}}$ série, que foram vinculados à disciplina de técnicas agrícolas. Realizou-se o preparo do terreno com a delimitação da área dos canteiros, seleção das espécies que seriam cultivadas e organização da disposição das plantas em cada canteiro e também a construção de estufas para proteção das mudas das oscilações de temperatura frequentes no estado do Rio Grande do Sul.

Paralelamente ao preparo da horta, foram feitos esclarecimentos sobre as plantas, os nutrientes que precisam e o uso aconselhado de cada espécie. Após a conclusão da horta, foi realizada uma atividade intitulada "tarde do chá", com a participação de toda a comunidade escolar, pais, alunos, professores e funcionários da escola. Nessa tarde, além do consumo de chás, foram esclarecidas dúvidas sobre as plantas, a quantidade que pode ser consumida, as contraindicações, a importância da identificação correta e também foi disponibilizada uma cartilha informativa sobre as espécies medicinais.

\section{Atividades na escola B}

Após análise dos questionários, os alunos interessados foram convidados a participar de oficinas sobre as espécies medicinais. Foram realizadas diferentes atividades, como apresentação das espécies citadas nos questionários, oficinas de preparo de chás e elaboração de cartazes informativos. Após essas atividades, realizou-se o cultivo de algumas espécies em garrafas pet, devido a não disponibilização de espaço apropriado pela escola.

\section{Atividades na escola $C$}

Nesta escola, fez-se a apresentação das plantas mais citadas e atividades recreativas, como um teatro sobre o uso das plantas medicinais e diferentes tipos de preparo de chás. Também foram repassados conceitos básicos sobre a importância dos nutrientes e o espaçamento adequado para o cultivo de espécies medicinais.

Em levantamento etnobotânicos é impor-

Idade: __ $\mathbf{N}^{\mathbf{0}}$ de pessoas que moram na casa:

- Utiliza plantas em sua residência:

( ) Sim ( ) Não

- De que forma:
( ) Alimentação
( ) Temperos
( ) Uso medicinal

- Das que você usa como medicinal, cite-as:

\begin{tabular}{l|l|l|l|l}
\hline Planta & Modo & Procedência & Usa para & Qual parte da planta e como usa ? \\
\hline $\begin{array}{l}\text { ( )seca } \\
\text { ( ) fresca }\end{array}$ & $\begin{array}{l}\text { ( ) da horta } \\
\text { ( ) do mato } \\
\text { ( ) comércio }\end{array}$ & & \\
\hline
\end{tabular}

Figura 1: Questionário

fonte autores 
tante calcular a importância de usos de uma planta, pois esse valor permite avaliar a importância das plantas para determinada comunidade, além de permitir a comparação dos usos entre diferentes populações. Foi calculado o valor de uso para todas as espécies, esse representado por (VU) conforme referido por Phillips \& Gentry (1993). Para o cálculo do valor de uso de uma espécie foi utilizada a fórmula $=\sum U / \mathrm{n}$, onde $\mathrm{U}$ corresponde ao número de usos mencionados pelo informante para cada espécie e $\mathrm{n}$ ao número de informantes. O valor de uso foi multiplicado por 100 para obter o percentual de uso de cada espécie.

\section{RESULTADOS E DISCUSSÃO}

Dos questionários distribuídos, 100 foram respondidos e devolvidos para análise. A porcentagem de participação de cada escola variou, na escola A foram entregues 30 questionários e 22 (73\%) retornaram. $\mathrm{Na}$ escola $\mathrm{B}$, no total de 180 questionários entregues, $59(32 \%)$ retornaram e na escola $C$ foram entregues 90 questionários e retornaram $19(21 \%)$.

TABELA 1: Espécies medicinais citadas nos questionários organizadas em ordem alfabética de nome científico, famílias, nomes populares e a escola onde cada espécie foi citada. As escolas estão representadas pelas letras A (escola A), B (escola B) e C (escola C), município de Palmeira das Missões, RS.

\begin{tabular}{|l|l|l|}
\hline Nome científico/ Família botânica & Nome popular & Escola \\
\hline Achillea millefolium L./ Asteraceae & Pronto-alívio & A, B e C \\
\hline Achyrocline satureioides (Lam.) DC./ Asteraceae & Marcela ou macela & A, B e C \\
\hline Aloe arborescens Mill./ Xanthorroeaceae & Babosa & A, B e C \\
\hline Aloysia citrodora Ortega ex Pers./ Verbenaceae & Cidró & A e B \\
\hline Aloysia gratissima (Gillies \& Hook.) Tronc./ Verbenaceae & Erva da colônia & B \\
\hline Ammi visnaga (L.) Lam./ Apiaceae & Aipo & A, B e C \\
\hline Aristolochia triangularis Cham./ Aristolochiaceae & Cipó-milome & A, B e C \\
\hline Artemisia absinthium L./ Asteraceae & Losna & A, B e C \\
\hline Artemisia alba Turra/ Asteraceae & Alcanflor & A \\
\hline Averrhoa carambola L./ Oxalidaceae & Carambola & A \\
\hline Baccharis articulata (Lam.) Pers/ Asteraceae & Carqueja & A e B \\
\hline Bauhinia forficata Link/ Fabaceae & pata-de-vaca & A, B e C \\
\hline Bidens pilosa L. / Asteraceae & Picão & A e C \\
\hline Calendula officinalis L./ Asteraceae & Calêndula & B \\
\hline Chamomilla recutita (L.) Rauschert/ Asteraceae & Camomila ou maçanilha & A, B e C \\
\hline Cinnamomum zeylanicum Blume / Lauraceae & Canela & A, B e C \\
\hline Cissus verticillata (L.) Nicolson \& C.E. Jarvis / Vitaceae & Penicilina & B \\
\hline Citrus aurantiifolia (Christm.) Swingle / Rutaceae & Lima & A e B \\
\hline Citrus reticulata Blanco / Rutaceae & Bergamota & A, B e C \\
\hline
\end{tabular}


TABELA 1: continuação...

\begin{tabular}{|c|c|c|}
\hline Nome científico/ Família botânica & Nome popular & Escola \\
\hline Citrus sinensis (L.) Osbeck / Rutaceae & Laranja & $\mathrm{A}, \mathrm{B}$ e $\mathrm{C}$ \\
\hline Coronopus didymus (L.) Sm. / Brassicaceae & Mentruz & $\mathrm{A}$ e B \\
\hline Cunila microcephala Benth. / Lamiaceae & Poejo & $\mathrm{A}, \mathrm{B}$ e $\mathrm{C}$ \\
\hline Cymbopogon citratus (DC.) Stapf / Poaceae & Cidreira & $\mathrm{A}, \mathrm{B}$ e $\mathrm{C}$ \\
\hline Cynara scolymus L. / Asteraceae & Alcachofra & $\mathrm{C}$ \\
\hline $\begin{array}{l}\text { Echinodorus grandiflorus (Cham. \& Schltdl.) Micheli / } \\
\text { Alismataceae }\end{array}$ & Chapéu-de-couro & $\mathrm{A}, \mathrm{B}$ e $\mathrm{C}$ \\
\hline Equisetum hyemale L. / Equisetaceae & Cavalinha & $\mathrm{Ae} \mathrm{B}$ \\
\hline Erythrina crista-gali L. / Fabaceae & Corticeira & $\mathrm{A}$ \\
\hline Eucalyptus globulus Labill / Myrtaceae & Eucalipto & $\mathrm{A}$ e $\mathrm{C}$ \\
\hline Eugenia uniflora L. / Myrtaceae & Pitanga & $\mathrm{A}, \mathrm{B}$ e $\mathrm{C}$ \\
\hline Foeniculum vulgare Mill. / Apiaceae & Funcho & $\mathrm{A}, \mathrm{B}$ e $\mathrm{C}$ \\
\hline Gochnatia polymorpha (Less.) Cabrera/Asteraceae & Cambará & $\mathrm{B}$ e $\mathrm{C}$ \\
\hline Hedychium coronarium J. Konig/ Zingiberaceae & Gengibre & $\mathrm{A}, \mathrm{B}$ e $\mathrm{C}$ \\
\hline Ilex paraguariensis A.St.-Hil./ Aquifoliaceae & Erva-mate & $\mathrm{A}$ \\
\hline Julocroton humilis Müll. Arg./ Euphorbiaceae & Velame & $\mathrm{A}$ e $\mathrm{C}$ \\
\hline Juncus capillaceus Lam./ Juncaceae & Pelo-de-porco & A \\
\hline Lavandula angustifolia Mill./ Lamiaceae & Alfazema & $\mathrm{A}$ e B \\
\hline Luehea divaricata Mart./ Malvaceae & Açoita-cavalo & $\mathrm{B}$ \\
\hline Malva parviflora L./ Malvaceae & Malva & $\mathrm{A}, \mathrm{B}$ e $\mathrm{C}$ \\
\hline Maytenus ilicifolia (Schrad.) Planch./ Celastraceae & $\begin{array}{l}\text { Cancorosa ou espinheira- } \\
\text { santa }\end{array}$ & A e C \\
\hline Melissa officinalis L./ Lamiaceae & Melissa & $\mathrm{A}, \mathrm{B}$ e $\mathrm{C}$ \\
\hline Mentha x piperita L./ Lamiaceae & Hortelã & $\mathrm{A}, \mathrm{B}$ e $\mathrm{C}$ \\
\hline Mikania laevigata Sch. Bip. ex Baker/ Asteraceae & Guaco & $\mathrm{A}, \mathrm{B}$ e $\mathrm{C}$ \\
\hline Nasturtium officinale R.Br./Brassicaceae & Agrião & $\mathrm{A}$ e B \\
\hline Origanum majorana L./ Lamiaceae & Manjerona & $\mathrm{A}, \mathrm{B}$ e $\mathrm{C}$ \\
\hline Origanum vulgare L./ Lamiaceae & Orégano & A \\
\hline Passiflora edulis Sims./ Passifloraceae & Maracujá & $\mathrm{A}$ e C \\
\hline Persea americana Mill./ Lauraceae & Abacate & $\mathrm{A}, \mathrm{B}$ e $\mathrm{C}$ \\
\hline Petroselinum crispum (Mill.) Fuss/ Apiaceae & Salsa & $\mathrm{A}, \mathrm{B}$ e $\mathrm{C}$ \\
\hline Phyllanthus tenellus Roxb./ Phyllantaceae & Quebra-pedra & $\mathrm{A}, \mathrm{B}$ e $\mathrm{C}$ \\
\hline Pimpinella anisum L./ Apiaceae & Erva-doce & $\mathrm{A}, \mathrm{B}$ e $\mathrm{C}$ \\
\hline Plantago major L./ Plantaginaceae & Transagem & $\mathrm{A}, \mathrm{B}$ e $\mathrm{C}$ \\
\hline Plectranthus barbatus Andrews/ Lamiaceae & Boldo & $\mathrm{A}, \mathrm{B}$ e $\mathrm{C}$ \\
\hline Polygonum hydropiperoides Michx./ Polygonaceae & Erva-de-bicho & A \\
\hline Pterocaulon polystachyum DC. / Asteraceae & Quitoco & $\mathrm{C}$ \\
\hline Punica granatum L./ Lythraceae & Romã & $\mathrm{A}, \mathrm{B}$ e $\mathrm{C}$ \\
\hline Rosmarinus officinalis L./ Lamiaceae & Alecrim & $\mathrm{A}, \mathrm{B}$ e $\mathrm{C}$ \\
\hline Ruta graveolens L./ Rutaceae & Arruda & $\mathrm{A}$ e B \\
\hline
\end{tabular}


TABELA 1: continuação...

\begin{tabular}{|l|l|l|}
\hline Nome científico/ Família botânica & Nome popular & Escola \\
\hline Salvia officinalis L./ Lamiaceae & Sálvia & A, B e C \\
\hline Solanum paniculatum L./ Solanaceae & Jurubeba & C \\
\hline Stachys byzantina C. Koch/ Lamiaceae & Cataflam & B \\
\hline Symphytum officinale L./ Boraginaceae & Confrei & A e B \\
\hline Syzygium cumini (L.) Skeels/ Myrtaceae & Jambolão & A \\
\hline $\begin{array}{l}\text { Handroanthus impetiginosa } \text { (Mart. ex DC.) Stand/ } \\
\text { Bignoniaceae }\end{array}$ & Ipê-roxo & A \\
\hline Tanacetum parthenium (L.) Sch. Bip/ Asteraceae & & Artimija \\
\hline Tanacetum vulgare L./ Asteraceae & Catinga-de-mulata & A \\
\hline Taraxacum officinale F.H. Wigg. /Asteraceae & Dente-de-leão & C B \\
\hline Urera baccifera (L.) Gaudich. ex Wedd./ Urticaceae & Urtigão & B \\
\hline Vitex megapotamica (Spreng.) Moldenke/ Lamiaceae & Tarumã & A e C \\
\hline Waltheria douradinha A. St.-Hil./ Malvaceae & Douradinha & C \\
\hline
\end{tabular}

As 69 espécies identificadas estão distribuídas em 33 famílias botânicas. As famílias com maior número de espécies citadas foram Asteraceae (15) e Lamiaceae (11). Essas frequentemente se destacam em levantamentos etnobotânicos como o Garlet (2000), em Cruz Alta, e de Vendrúscolo e Mentz (2006) no Bairro Ponta Grossa, em Porto Alegre.

A escola que apresentou maior diversidade de citações foi a escola A, mesmo possuindo um número reduzido de alunos. Pode-se considerar que esse fato está relacionado ao contato direto da comunidade com o meio rural, consequentemente com as plantas. Esse convívio diário favorece tal conhecimento.

Conforme Vendrúscolo e Mentz (2006) em estudos etnobotânicos, o valor de uso estabelece a importância de determinada espécie para a comunidade estudada, quanto maior a porcentagem de uso, independente da categoria mencionada para a espécie maior será a sua importância. No presente estudo, calculou-se a porcentagem de uso para todas as espécies citadas, sendo posteriormente discriminadas as dez espécies com maior valor de uso em cada escola, os resultados estão representados graficamente na figura 2 .

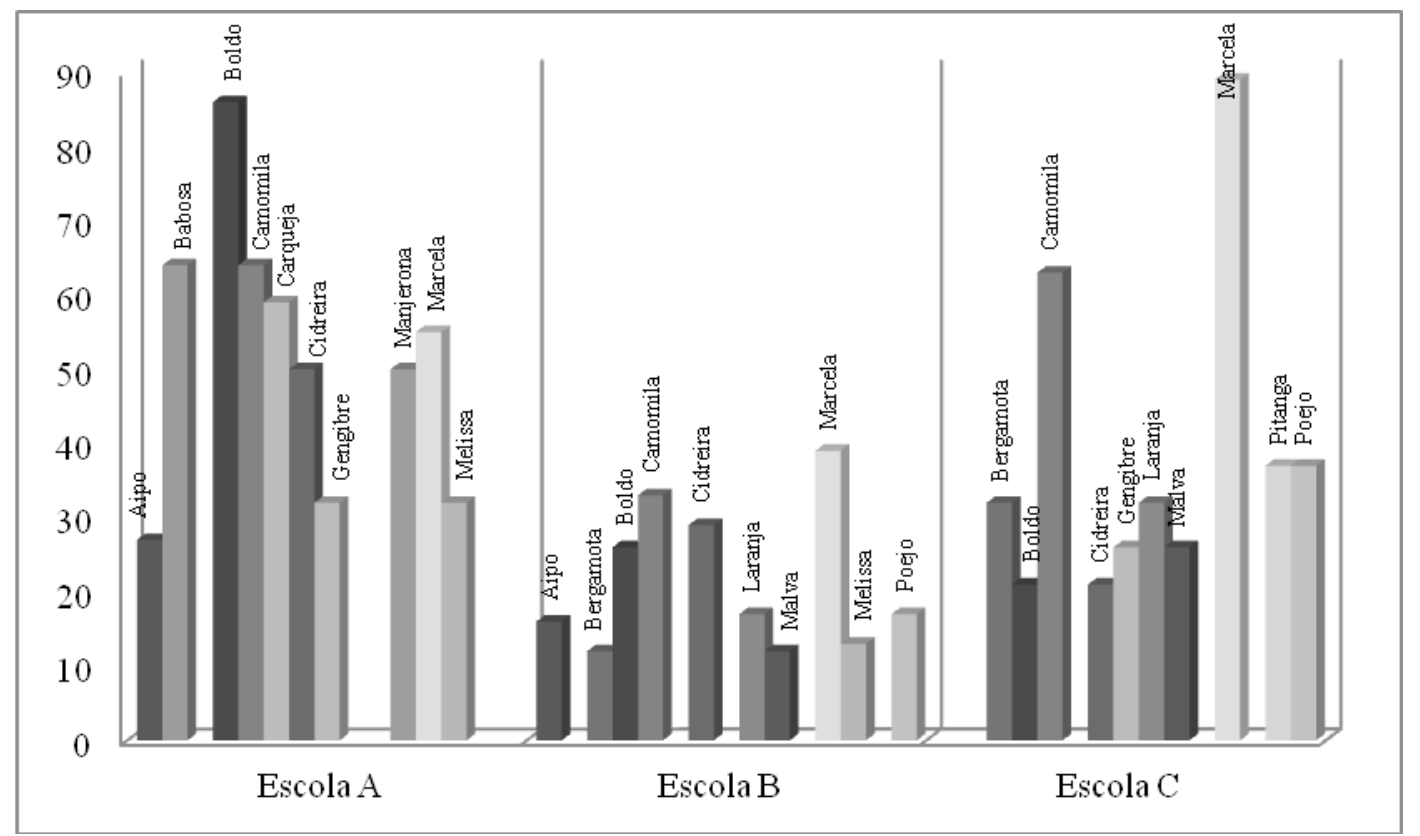

Figura 2: Representação gráfica das dez espécies com maior porcentagem de uso em três escolas do município de Palmeira das Missões, RS. 
As espécies de maior importância de uso coincidem nas escolas B e C, sendo essas Achyrocline satureioides (marcela) e Chamomilla recutita (camomila), na escola A o Plectranthus barbatus (boldo) se destaca com a maior importância de uso. Para essas espécies os usos mais citados foram para o tratamento de problemas gastrointestinais (boldo e marcela) e como calmante (camomila).

Observou-se que o interesse e o engajamento da comunidade escolar em geral foram determinantes para o sucesso do estudo. Segundo Silva (2011), o tamanho da escola, número de alunos e de professores, predisposição destes professores em passar por um processo de treinamento, vontade da direção de realmente programar um projeto ambiental que vá alterar a rotina na escola, além do resultado da integração entre todos esses fatores podem servir como obstáculos à implantação dos espaços verdes medicinais como ferramenta de Educação Ambiental.

As etapas subsequentes do estudo variaram de acordo com a estrutura de cada escola. Na escola A, que está situada na zona rural do município, o acesso é dificultoso, mas o espaço físico é amplo. Porém, já possui uma horta alimentícia implantada, facilitando a incorporação das espécies medicinais, além disso, destacou-se nessa escola o interesse da comunidade escolar em participar efetivamente das atividades propostas. Os professores da escola se encontravam favoráveis à implantação de novas ideias e propostas diferenciadas, favorecendo a execução do trabalho. Dentre as atividades educativas propostas e realizadas, destacaram-se a capacitação dos alunos sobre o tema plantas medicinais, atividades como elaboração e diagnóstico das condições da área onde os canteiros deveriam ser implantados, planejamento e construção dos canteiros, seleção das plantas mais adequadas a esse espaço, reforço ao reaproveitamento dos resíduos orgânicos produzidos na cozinha da escola (composteira), como o sol e a água agem sobre as plantas e influenciam o seu crescimento, a importância dos nutrientes no solo, o cultivo de algumas espécies medicinais e a construção de uma estufa. As espécies cultivadas foram cidró, hortelã, poejo, manjerona, cidreira, losna, carqueja, alcachofra, boldo, salsa, alecrim, alfazema, guaco, arruda, pariparoba, orégano e malva. Para finalizar as atividades na escola A realizou-se a tarde do chá integrando toda a comunidade escolar. Os chás foram preparados a partir das plantas cultivadas pelos estudantes na horta da escola.

$\mathrm{Na}$ escola B, localizada na periferia do município, a estrutura é desfavorecida e o espaço físico a ser aproveitado é limitado, além disso, não houve participação efetiva do corpo docente, afetando o bom desenvolvimento do estudo. Dentre as atividades educativas propostas e realizadas destacaram-se a apresentação das plantas medicinais, elaboração pelos alunos de cartazes informativos, capacitação dos alunos a respeito do uso das plantas, oficina de preparo de chás, importância dos nutrientes no solo, influência da água e do sol no crescimento da planta, o cultivo de algumas espécies medicinais em garrafas pet. As espécies cultivadas foram alecrim, alfazema, babosa, boldo, camomila, cavalinha, guaco, melissa e poejo.

A escola $C$, que também está localizada na periferia do município, a estrutura física é boa, porém mal utilizada, as atividades foram realizadas paralelamente com a disciplina de ciências. As atividades educacionais propostas foram mais lúdicas devido à faixa etária do público atendido. Destacaram-se a apresentação das plantas medicinais, oficinas de preparo de chás, teatros sobre os usos de plantas medicinais, realização da limpeza e organização do espaço para cultivo, porém o cultivo efetivamente não foi realizado devido ao término do ano letivo.

Nas escolas onde as atividades não foram estendidas a toda a comunidade escolar, conforme proposto no início do trabalho, considerou-se como fator determinante o engajamento do corpo docente. Segundo Silva (2011), a valorização do conhecimento é papel dos educadores na rede de ensino para que este não se perca em relação aos saberes formais. O educador tem papel fundamental nas atividades extracurriculares das escolas, pois se encontra como mediador dos pais e alunos. $\mathrm{O}$ envolvimento dos pais gera interesse maior nos alunos, para isso é fundamental utilizar as oportunidades, nesse caso o espaço verde medicinal, proporcionando a multidisciplinaridade e incremento de conteúdos didáticos.

Sabe-se que uma horta medicinal, como espaço verde no ambiente escolar, pode vir a promover a integração entre os diversos conteúdos, além de melhorar o convívio social, pois estimula o respeito e o cuidado para obter bons resultados. Quando se implanta uma horta na escola, distribuem-sese distribuem funções aos alunos, estimulando-os ao trabalho em grupo. Dessa forma, observa-se que os projetos só têm resultados benéficos quando realizados de uma forma conjunta entre toda a comunidade escolar e os acadêmicos ali envolvidos.

Segundo Effting (2007), as ações ambientais devem ser praticadas na escola, na família e na 
sociedade. Os resultados obtidos concordam com essa afirmação, pois as atividades que engajaram toda a comunidade escolar incluindo os pais dos alunos foram as que tiveram resultados mais positivos e contínuos. Quando ocorre a busca pelo aprimoramento da capacidade de trabalho, com espírito cooperativo e com responsabilidade pelos atos praticados, desenvolve-se a consciência do individual e do coletivo no trabalho escolar, possibilitando a integração dos alunos com a questão ambiental (FETTER, 2007).

Acredita-se que, com a implantação dos espaços verdes medicinais, a comunidade escolar tenha sido sensibilizada sobre a importância da utilização adequada das espécies, em especial os alunos participantes das atividades, que por meio de suas vivências podem ser agentes multiplicadores das experiências adquiridas e podem auxiliar na conservação da biodiversidade e do meio ambiente.

Além disso, sabe-se que as atividades de extensão são importantes na formação dos cidadãos, tanto no ambiente escolar quanto na academia, pois expressam a concepção que considera o estudante como sujeito da construção de seu próprio conhecimento e não receptor passivo da transmissão de conhecimento (Freire, 2006). As atividades extensão de certa forma dão um novo rumo à universidade no sentido de estar próxima à população e poder contribuir para uma mudança significativa, não só da comunidade, mas da sociedade em si. Essa relação funciona na reciprocidade em que a universidade leva conhecimentos e/ou assistência à comunidade, atendendo suas necessidades e proporciona o aprendizado com o saber e a cultura popular, que engrandece o conhecimento de quem dela participa (ROSSATO et al., 2012).

$\mathrm{O}$ estudo desenvolvido foi de grande relevância na realidade de cada escola. A implantação dos espaços verdes com espécies medicinais, condimentares e aromáticas, além da transmissão do conhecimento, proporcionou a fixação desse tema em toda a comunidade atendida e também resgatou a preocupação com a preservação da biodiversidade local, pois as atividades reforçaram a importância das plantas nos cuidados básicos com a saúde.

\section{AGRADECIMENTOS}

Os autores agradecem pela concessão de bolsas do Programa FIEX da Universidade Federal de Santa Maria.

\section{REFERÊNCIAS BIBLIOGRÁFICAS}

AMOROZO, M. C. M. Abordagem etnobotânica na pesquisa de plantas medicinais. In: DI STASI, L.C. (Org.) Plantas medicinais: arte e ciência. Um guia de estudos interdisciplinar. São Paulo: UNESP. 1996.

BRASIL. Ministério da Saúde. Política Nacional de Plantas Medicinais e Fitoterápicos. Ministério da Saúde/Secretaria de Ciência, Tecnologia e Insumos Estratégicos, Departamento de Assistência Farmacêutica. Brasília, 2006.

BRASIL. Ministério da Educação. Orientações para implantação e implementação de hortas escolares. Fundo Nacional de Desenvolvimento da Educação/ Ministério da Educação. Brasília, 2007.

DI STASI, L. C. Plantas medicinais: arte e ciência. Um guia de estudo interdisciplinar. São Paulo: UNESP. 1996.

EFFTING, T. R. Educação Ambiental nas Escolas Públicas: Realidade e Desafios. Marechal Cândido Rondon, 2007. Monografia (Pós Graduação em Lato Sensu Planejamento Para o Desenvolvimento Sustentável) - Centro de Ciências Agrárias, Universidade Estadual do Oeste do Paraná - Campus de Marechal Cândido Rondon, 2007.

FETTER, S. I.; MULLER, J. Agroecologia, merenda escolar e ervas medicinais - Resgatando valores no ambiente escolar. Revista Brasileira de Agroecologia, Porto Alegre, v. 2, n.1, p. 18-321, 2007.

FREIRE, P. Extensão ou Comunicação. 13.ed. São Paulo: Paz e Terra. 2006.

GARLET, T. M. B. Levantamento das plantas medicinais utilizadas no município de Cruz Alta, RS, Brasil. Porto Alegre, PPG Botânica/UFRGS, Dissertação Mestrado, 220p. 2000.

LEITA, M. T. F.; NUNES, B. M. V. T. Centro rural universitário de treinamento e ação comunitária Um resgate histórico 1975-1986. Texto \& Contexto Enfermagem. Florianópolis, v.18, n.3, p.427, 2009.

MATOS, E.; DE QUEIROZ, L. P. Árvores para cidades. Salvador: Ministério Público do Estado da Bahia, 2009.

MORGADO, F. S.; SANTOS, M. A. A. A horta escolar na educação ambiental e alimentar: expe- 
riência do Projeto Horta Viva nas escolas municipais de Florianópolis. Extensio: Revista Eletrônica de Extensão. v.5, n.6, 2009.

NEVES, J. D. S.; SILVA, C. G.; BARROS, R. P. Experiência de Gestão e Educação Ambiental no projeto Farmácia Viva em duas Escolas. In: Anais... $1^{\circ}$ SIMAGA - Simpósio Alagoano de Gestão Ambiental, Arapiraca-AL, Brasil, 31 maio a 04 de junho de 2010, UNEAL/CAMPUS I, p. 21-30. CD ROM ISSN 2177-7268.

PHILLIPS, O.; GENTRY, A. H. The useful plants of Tambopata, Peru: I. Statistical hypotheses tests with a new quantitative technique. Economic Botany, v. 47, n. 1, p. 15-32, 1993.

ROCHA, R. M. G. A Construção do Conceito de Extensão Universitária na America Latina. In: Construção Conceitual da Extensão na America Latina. FARIA, D.S (Org). Brasília: UNB. p.13-29, 2001.

ROSSATO, A.; CHAVES, T. R. C. Fitoterapia Racional: Aspectos Taxonômicos, Agroecológicos, Etnobotânicos e Terapêuticos. Florianópolis: DIOESC. v.1, 2012.

SILVA, C. G.; NEVES, J. D. S.; BARROS, R. P. Atividades de extensão universitária na formação de professores de ciências biológicas: uma narrativa do projeto farmácia viva e educação ambiental. V Colóquio Internacional "Educação e contemporaneidade". São Cristóvão - Se/Brasil - 21 a 23 de Setembro de 2011.

VENDRÚSCOLO, G. S.; MENTZ, L. A. Levantamento etnobotânico das plantas utilizadas como medicinais por moradores do bairro Ponta Grossa, Porto Alegre, Rio Grande do Sul, Brasil. Iheringia Série Botânica v. 61, p.83-103, 2006. 